\title{
Links between Perinatal Risk Factors and Maternal Psychological Distress: A Network Analysis
}

\author{
Lydia Gabriela Speyer ${ }^{\mathrm{a}}$, Hildigunnur Anna Hall ${ }^{\mathrm{a}}$, Anastasia Ushakova ${ }^{\mathrm{a}, \mathrm{b}}, \mathrm{PhD}, \mathrm{Aja}$ \\ Louise Murray $^{\mathrm{a}}, \mathrm{PhD}$, Michelle Luciano ${ }^{\mathrm{a}}, \mathrm{PhD}$, and Bonnie Auyeung ${ }^{\mathrm{a}, \mathrm{c}}, \mathrm{PhD}$
}

\begin{abstract}
Affiliations: ${ }^{a}$ Department of Psychology, University of Edinburgh, Edinburgh, United Kingdom; ${ }^{b}$ Department of Psychology, University of Lancaster, Lancaster, United Kingdom; and ${ }^{\mathrm{c}}$ Autism Research Centre, Department of Psychiatry, University of Cambridge, Cambridge, United Kingdom
\end{abstract}

Address correspondence to: Lydia Gabriela Speyer, Department of Psychology, University of Edinburgh, 7 George Square, Edinburgh, EH8 9JZ, United Kingdom, [1speyer@ed.ac.uk, $00436506914172]$. 
Conflicts of interest/Competing interests:

The authors have no conflicts of interest relevant to this article to disclose. 


\section{Funding:}

The Millennium Cohort Study is funded by the UK Economic and Social Research Council (ES/M001660/1). Lydia Gabriela Speyer was funded by the University of Edinburgh through a Principal's Careers Development Scholarship. Hildigunnur Anna Hall was funded by the UK Economic and Social Research Council (ES/R500938/1). Bonnie Auyeung was supported by the European Union's Horizon 2020 research and innovation programme under the Marie Skłodowska-Curie grant agreement No.813546, the Baily Thomas Charitable Fund TRUST/VC/AC/SG/469207686, and the UK Economic and Social Research Council (ES/N018877/1) during the course of this work. The study sponsors had no part in the design, data analysis and interpretation of this study, in the writing of the manuscript or in the decision to submit the paper for publication, and the authors' work was independent of their funders. 
Ethics approval: Data used in this study came from sweep one of the Millennium Cohort Study which was approved by the National Health Service Ethical Authority in February 2001: MREC/01/6/19.

Consent to participate: Not applicable

Consent for publication: Not applicable

Availability of data and material: The University of London Centre for Longitudinal Studies owns the copyright for the Millennium Cohort Study (MCS) data used in this study. The MCS data are held/curated by the UK Data Service. Anyone wishing to use the MCS data (found at: https://discover.ukdataservice.ac.uk/series/?sn=2000031) must register and submit a data request to the UK Data Service at http://ukdataservice.ac.uk/. Additional terms and conditions of access are outlined here: https://www.ukdataservice.ac.uk/get-data/how-toaccess/conditions.

Code availability: The restructuring and merging script is provided on GitHub: https://github.com/Lydia-G-S/Millennium-Cohort-Study-Data-Restructuring-in-R

Authors' contributions: LGS conceptualized and designed the study, conducted analyses, drafted the initial manuscript, and reviewed and revised the manuscript. HAH and AU made substantial contributions to analysis and interpretation of data and critically reviewed the manuscript for important intellectual content. ALM, ML and BA made substantial contributions to the conception and design of the study and critically reviewed the manuscript for important intellectual content. All authors approved the final manuscript as submitted and agree to be accountable for all aspects of the work. 


\section{Abstract}

Introduction: This paper explores a range of perinatal risk factors that may increase maternal vulnerability to postnatal psychological distress in a sample of 17531 women participating in the Millennium Cohort Study, a diverse British, longitudinal birth cohort study.

Materials and Methods: Using a graphical network modelling framework, this study models links between postnatal psychological distress and perinatal risk factors while controlling for socio-demographic factors and history of depression and anxiety. Postnatal psychological distress was assessed at nine-months post-partum using the Rutter Malaise Inventory.

Results: Results of the graphical network models indicate that lower levels of happiness about the pregnancy (Edge weight $(w)=0.084, C I=0.069$ to $0.100, b=0.095$ ), smoking during pregnancy $(w=0.026, C I=-0.009$ to $0.060, b=0.029)$, infection during pregnancy $(w=0.071$, $C I=0.024$ to $0.118, b=0.090$ ), hyperemesis gravidarum ( $w=0.068, C I=0.013$ to $0.123, b=0.083$ ), baby in special care $(w=0.048, C I=-0.004$ to $0.099, b=0.062)$, not being White $(w=0.101$, $\mathrm{CI}=0.062$ to $0.140, \mathrm{~b}=0.118)$, being from a more deprived area $(w=-0.028, C I=-0.051$ to -0.005 , $b=-0.039)$, lower income ( $w=-0.025, C I=-0.055$ to $0.005, b=-0.036)$ and history of depression or anxiety $(w=0.574, C I=0.545$ to $0.603, b=0.764)$ are associated with increased psychological distress.

Conclusion: While some perinatal risk factors may be directly associated with postnatal psychological distress, many risk factors appear to be primarily associated with demographic factors. This emphasizes the importance of taking a holistic approach when evaluating an individual's risk of developing postnatal psychological distress. 
Keywords: pregnancy; perinatal risk factors; postnatal psychological distress; graphical model; millennium cohort study

\author{
Abbreviations: \\ PD - postnatal psychological distress \\ MCS - Millennium Cohort Study \\ RMI - Rutter Malaise Inventory
}

Key Message: Most perinatal risk factors are primarily associated with demographic factors. History of depression or anxiety seems to be the strongest risk factor for postnatal psychological distress. A holistic approach is needed when evaluating an individual's risk of developing postnatal depression. 


\section{Introduction}

Depressive symptoms are one of the most common health problems for women in the postnatal period, affecting around 10 to 18 percent of women and ranging in severity from 'maternity blues' to a clinical diagnosis of postpartum depression ${ }^{1,2}$. Evidence suggests that postpartum depression may affect not only women's health and wellbeing but also their children's cognitive and behavioral development ${ }^{3,4}$. Previous research has identified a wide array of risk factors for postnatal psychological distress (PD), most focusing on socio-demographic risks and on history of mental health difficulties which have been associated with higher risks of developing postnatal depression ${ }^{5-8}$. However, less attention has been paid to the role of perinatal risk factors in postnatal mental health difficulties with existing studies finding conflicting evidence ${ }^{9-11}$. Further, many analyses used in previous studies were limited in that they focused on the relations between postnatal maternal mental health and one specific focal risk factor, which ignores potential confounding and risk factor relations. Thus, findings on individual risk factors might be misleading and differ when a broader range of additional risk factors are taken into account. An alternative approach to analyzing the effect of perinatal risk factors on PD is an integrated analysis that looks at the relations of all variables at once in the form of a graphical model ${ }^{12}$.

This study aims to explore a wide range of perinatal factors that may increase maternal vulnerability to postnatal depression, using data acquired in the Millennium Cohort Study (MCS). In addition to using traditional analysis strategies such as regressions to model the relations between individual risk factors and $\mathrm{PD}$, this study uses a graphical network approach to model the dependencies between all risk factors and thereby provides a more comprehensive understanding of how these risk factors are connected to each other as well as to maternal mental health difficulties. The results of this study extend the postpartum depression literature and contribute to a better understanding of perinatal risk factors that are associated with an increased risk of developing postnatal mental health problems. We further show that network based analysis might be preferable for researchers working in this or similar domains, given its obvious strengths with respect to appropriately accounting for dependence structures in relations among multiple variables while still offering an intuitive visualisation and interpretation.

\section{Materials and Methods}




\subsection{Design and Study Population}

The MCS is a longitudinal, nationally representative study of around 19,000 children born in the United Kingdom. To date, there have been seven sweeps of data collection starting in 2001 when the children were around nine-months old ( $\mathrm{N}=18,553$ families). For details, see MCS documentation $^{13}$. The current study included biological mothers who completed the Rutter Malaise Inventory (RMI), a measure of psychological distress, at nine-months postpartum. Mothers with missing data on the RMI $(\mathrm{N}=765)$ and mothers of multiples $(\mathrm{N}=226)$ were excluded, which resulted in a final sample size of 17531 women.

\subsection{Measures}

\section{Outcome}

Postnatal psychological distress was measured through interviews which took place ninemonths post-delivery using a 9-item scale adopted from the Rutter Malaise Inventory (RMI) ${ }^{14}$. For details, please see the online supporting information.

\section{Risk factors}

A wide range of potential perinatal risk factors were ascertained nine-months after delivery from maternal self-reports. All available risk factors measured in the MCS were included to allow for a comprehensive analysis. Women were asked whether the pregnancy was planned, whether they had fertility treatment, how they felt when they became pregnant (scale from 1 to 5, 1 indicating very happy, 5 indicating very unhappy), whether they received antenatal care and whether they attended antenatal classes. They further indicated the place of birth (home or hospital), the type of delivery (normal, assisted, planned cesarean, emergency cesarean, other), type of pain medication (none, epidural, gas and air, opiate injection, other) and whether the labour was induced. Women were furthermore asked whether there were any complications during labour (abnormal lie, very long labour, very rapid labour, fetal distress), whether they had any illness during pregnancy (infections (urinary tract infection or other/non-trivial infection), hyperemesis gravidarum, diabetes, preeclampsia, anemia, bleeding in early pregnancy, bleeding in late pregnancy) and whether they smoked during pregnancy. They also indicated the sex of the baby, whether the new-born had to spend time in special care, when the new-born came home (age in days after leaving hospital), and how many weeks they breastfed. In addition, gestational age in days and birth weight in kilo-grams were derived from hospital records at the time of birth. For wording of interview questions on maternal illness during pregnancy, please see the online supporting information. 


\section{Covariates}

A priori confounders that previous research has shown to be associated with postnatal psychological distress included maternal age, level of education, ethnicity, whether the mother is a single parent, whether the mother is a first time mother, socio-economic status, maternal attachment, and history of depression and anxiety ${ }^{5-7}$. Age, ethnicity (White or other ethnicity), education (equivalent of National Vocational Qualification level 1 or above Yes/No), whether the mother is a single parent, whether they are first time mothers and their history of depression or anxiety ("Has a doctor ever told you that you suffer from depression or serious anxiety?") were all ascertained from maternal self-reports at nine-months post-partum. The index of multiple deprivation (IMD) and weighted OECD equivalised income quintiles were derived as measures of socio-economic status ${ }^{15}$.

\subsection{Statistical Analyses}

To analyze the relations between the individual perinatal risk factors and psychological distress at nine-months post-partum, simple linear regressions were fitted and then extended using multiple linear regressions, accounting for all socio-demographic covariates as well as for history of depression or anxiety. To control for multiple comparisons, significance was accepted at a Bonferroni corrected alpha level of .001. In addition, all regression models were adjusted for the complex survey design of the Millennium Cohort Study based on the recommendations given in the MCS guidelines ${ }^{16}$. To extend the traditional methodological framework, this study proposes the use of Pairwise Markov Random Field (PMRF) models to model the dependencies between risk factors and maternal psychological distress. Two such models were built: one model only included the perinatal risk factors and another model also included sociodemographic factors and history of maternal depression or anxiety. Models were estimated using the R package $\mathrm{mgm}^{17}$. For details, see the online supporting information.

\subsection{Ethical approval}

Data used in this study came from sweep one of the Millennium Cohort Study which was approved by the National Health Service Ethical Authority in February 2001 $(\mathrm{MREC} / 01 / 6 / 19)^{18}$.

\section{Results}

\subsection{Descriptive Statistics}


On average, women were $28.79(S D=5.86)$ years old and scored $1.62(S D=1.73)$ on the Rutter Malaise Inventory. Characteristics of the study population are presented in Table 1 and Table 2 .

[Table 1 about here]

[Table 2 about here]

\subsection{Regression Analysis}

The univariate analysis showed that the following factors were associated with greater postnatal psychological distress after adjusting for multiple comparisons: unplanned pregnancy, not receiving antenatal care, not attending antenatal classes, lower levels of happiness about the pregnancy, induction of labour, infection during pregnancy, hyperemesis gravidarum, anemia during pregnancy, bleeding in early pregnancy, bleeding in late pregnancy, shorter duration of breastfeeding, baby in special care, smoking during pregnancy, lower birthweight, younger gestational age and baby coming home from hospital later. However, after adjusting for potential confounders, fertility treatment, attending antenatal classes, induction of labour and breastfeeding were no longer associated with PD, whereas abnormal lie, long labour and fetal distress were now associated with PD. Table 3 shows parameter estimates for risk factors that were predictors of PD in the multivariate analysis. For results of the univariate analysis and non-associated risk factors see the online supporting information Table S1.

[Table 3 about here]

\subsection{Network Analysis}

The first graphical model, which included all risk factors but did not adjust for demographic factors or maternal history of depression or anxiety, is displayed in Figure 1. It shows that lower levels of happiness about the pregnancy, not attending antenatal classes, induction of labour, baby in special care, smoking during pregnancy, infections during pregnancy and hyperemesis gravidarum share edges with maternal psychological distress, however these edges were not particularly strong (see supporting information Table S2). After adding demographic factors and history of depression or anxiety, PD was no longer related to attendance of antenatal classes and induction of labour. PD shared edges with income, 
deprivation, maternal ethnicity and history of depression or anxiety with the remaining variables being related to the outcome only indirectly through these variables (Figure 2).

[Figure 1 about here]

[Figure 2 about here]

To quantify the uncertainty associated with these edges, we used 1000 bootstrap samples to compute the $95 \%$ confidence intervals (CI) of the bootstrapped sampling distribution (see Table 4 for variables sharing an edge with PD in the adjusted model; for full results see the online supporting information Table S2 and Table S3). In the model including confounders, only the CI's for edges between hyperemesis gravidarum, infections during pregnancy, levels of happiness about the pregnancy, deprivation, maternal ethnicity, history of maternal depression or anxiety did not include zero, suggesting a high probability of these edges representing true relations. However, as we used LASSO regularization to estimate the graphical models, edge weights were already biased towards zero which means that the bootstrapped CI's were not centered on the true parameter value and the test is conservative ${ }^{19}$.

\section{[Table 4 about here]}

In addition to obtaining edge weights which offer information on the strengths of the relations between nodes (higher values indicate stronger associations between two variables), parameter estimates can be obtained to better understand the direction of relations (Table 4). These estimates can be interpreted as the expected change in standardized PD scores per one standard deviation increase in continuous variables or a change of level for categorical variables, when holding all other variables constant. These parameter estimates showed that having a history of depression or anxiety was associated with the biggest increase in psychological distress levels at nine-months postpartum, followed by not being White, lower levels of happiness about the pregnancy, having an infection during pregnancy, suffering from hyperemesis gravidarum, baby spending time in special care, living in a more deprived area, having lower income and having smoked during pregnancy.

Finally, we estimated node predictability which is visualized in the form of rings around nodes in Figures 1 and 2. Due to its ability to account for dependencies across predictors, the graphical 
model offered insights into the accuracy of the model for all variables, showing that maternal education, maternal ethnicity and history of depression or anxiety were particularly well explained by the other variables in the model as is indicated by the high accuracy of the model for these predictors $(85.1 \%, 88.5 \%$ and $78.4 \%$ respectively). For maternal PD, overall accuracy of the fully adjusted model was $17.1 \%$.

\section{Discussion}

This study used a graphical network modelling framework to gain unique insights into the relations between maternal psychological distress at nine-months postpartum and multiple perinatal and demographic risk factors as well as history of depression or anxiety. Identified perinatal risk factors for developing PD included: lower levels of happiness about the pregnancy, smoking during pregnancy, having an infection during pregnancy, suffering from hyperemesis gravidarum and having a baby that needs to spend time in special care. Apart from infections during pregnancy, these risk factors have been previously identified to be associated with PD. In line with previous research, our results further emphasize the role of history of depression and anxiety as the strongest risk factor for the development of $\mathrm{PD}^{3}$.

Several mechanisms might explain our findings. First, women tend to have particular expectations about the perinatal period. When these expectations are not met, for example when a baby requires hospitalization, women might struggle with unforeseen challenges (and may for example, experience feelings of failure) which can lead to the development of depressive symptoms or even post-traumatic stress ${ }^{20}$. This effect would probably be amplified in women who were not initially happy about being pregnant as they have been found to be more likely to struggle bonding with their child, which has been shown to mediate the relationship between negative attitudes towards pregnancy and $\mathrm{PD}^{21}$. Another potential mechanism for some of these findings is changes in physical morbidity. Suffering from hyperemesis gravidarum or having an infection during pregnancy can lead to pain, tiredness and reduced levels of activity which are well-known risk factors for experiencing depressive symptoms ${ }^{22}$. The association between infections and PD could potentially also be explained by changes in women's immune response following an infection. Lower levels of inflammatory markers, such as Interleukin-10, in late pregnancy have been shown to increase the risk of developing depressive symptoms postpartum $^{23}$. This mechanism could also come into play for hyperemesis gravidarum and 
smoking during pregnancy which have also been shown to be associated with changes in levels of inflammatory markers ${ }^{24,25}$.

The graphical network modelling approach provided increased insight into the relations between risk factors and PD compared to a typical linear regression analysis because it investigated risk factors and their relations to each other as well as with PD. The factors identified to be associated with PD in the network model were also found to be related to PD in the multiple regression analysis. However, many other risk factors identified by the regression analysis did not share an edge with PD in the fully adjusted network model, indicating a lack of direct relations between these risk factors and PD and suggesting that perhaps, while these factors may be correlated, they are not itself a source of variation in PD. This difference occurs because the graphical network model allows identification of conditional dependencies between variables simultaneously, rather than examining individual variables in isolation. For example, the node for planned pregnancy in Figures 1 and 2 is shown to be highly connected to receiving fertility treatment as well as to levels of happiness about the pregnancy. Hence, if accounting for all of these factors simultaneously there is no connection between PD and planned pregnancy as they are conditionally independent given levels of happiness about the pregnancy. This might be expected since a woman who had planned to get pregnant would be more likely to express happiness about the pregnancy ${ }^{26}$. Similarly, for receiving antenatal care, Figure 2 shows that it shares edges with maternal age, maternal education, maternal ethnicity and income. It is reasonable to assume that whether a woman receives antenatal care would be related to her socio-economic status, and all of these factors are related to the mother's $\mathrm{SES}^{27}$. Hence, PD is conditionally independent of receiving antenatal care given those demographic measures. The fully adjusted graphical model highlights that perinatal risk factors are often primarily associated with demographic factors and potentially only indirectly with PD, and thus, emphasizes the importance of taking a holistic approach when analyzing such relations as well as when evaluating an individual's risk of suffering from postnatal psychological distress.

This study is the first to use graphical models to investigate the links between perinatal risk factors, socio-demographic factors and history of depression or anxiety, and postnatal psychological distress. These methods offer much more detailed insights into the relations between risk factors and PD compared to more traditional methods such as linear regressions. Graphical models estimate all predictor, covariate and outcome relations simultaneously and 
test for multiple dependencies in the data, offering a novel perspective to the well-studied phenomena of postnatal psychological distress. Since the data used in our study was collected as part of a large UK-wide birth cohort study, our participants are based on a nationally representative sample of women, which enabled us to look at many potential risk factors and demographic factors simultaneously.

The main limitation is that all information on perinatal risk factors was collected retrospectively at nine-months postpartum and is based on women's self-reports. Hence, some of the data could have been subject to recall-error and the results should, therefore, be interpreted with caution. However, research on agreement between self-reports and medical records has generally been shown to be high (e.g. agreement of $\sim 90 \%$ for self-reported gestational diabetes) ${ }^{28}$, with a tendency for self-reports to underreport illnesses ${ }^{29}$. Thus, our findings might be more conservative than if we had relied on medical records. Postnatal depression typically has an onset soon after giving birth and is often resolved after several weeks or months ${ }^{30}$. This could mean that some mothers had suffered from postnatal depression and recovered by the time of assessment, which would lead to an under-reporting of PD and are therefore not captured adequately in this study. On the other hand, the women with higher PD scores in this study, may have suffered more severe and persistent symptoms of PD, putting them at greatest risk of adverse outcomes. Future studies should aim to replicate these findings using data based on hospital records or registry data. Also, the final model only accounted for $17.1 \%$ of the variance in PD scores, indicating the complexity of explaining PD using the combination of variables available in this paper. Future studies should look at additional factors that might affect PD to improve the overall explanatory power of the models.

\section{Conclusion}

This study shows that lower levels of happiness about the pregnancy, smoking during pregnancy, infections during pregnancy, hyperemesis gravidarum and induction of labour are associated with an increased risk of having high levels of psychological distress at nine-months postpartum. This study further underlines the recommendation that future research should take a comprehensive approach to analyzing risk factors. Future studies should also aim to analyze the pathways that lead to the observed associations with increased postnatal psychological distress and certain risk factors and should further focus on mitigations of PD that are targeted on a demographic basis. It is important that healthcare professionals working with mothers are 
aware of these risk factors for postnatal psychological distress as well as the increased risk for women from certain demographic groups. These women may benefit from earlier and more regular screening to facilitate timely intervention and to help prevent the maternal and child sequelae of postnatal psychological distress. 
Acknowledgements We are very grateful to all the families who took part in the Millennium Cohort Study, and the whole MCS team, which includes interviewers, computer and laboratory technicians, clerical workers, research scientists, and volunteers.

\section{Tweetable Abstract}

Perinatal risk factors often only indirectly associated with postnatal psychological distress important to take a holistic approach when analyzing postnatal mental health.

\section{Twitter handles:}

@ LydiaSpeyer

a_annahall

@apavluhina

@AjaLMurray

@bauyeung 


\section{REFERENCES}

1. O'Hara MW, McCabe JE. Postpartum Depression: Current Status and Future Directions. Annu Rev Clin Psychol. 2013;9(1):379-407. doi:10.1146/annurev-clinpsy$050212-185612$

2. Josefsson A, Berg G, Nordin C, Sydsjo G. Prevalence of depressive symptoms in late pregnancy and postpartum. Acta Obstet Gynecol Scand. 2001;80(3):251-251. doi:10.1080/j.1600-0412.2001.080003251.x

3. Robertson E, Grace S, Wallington T, Stewart DE. Antenatal risk factors for postpartum depression: A synthesis of recent literature. Gen Hosp Psychiatry. 2004;26(4):289-295. doi:10.1016/j.genhosppsych.2004.02.006

4. Stein A, Pearson RM, Goodman SH, et al. Effects of perinatal mental disorders on the fetus and child. Lancet. 2014;384(9956):1800-1819. doi:10.1016/S01406736(14)61277-0

5. Söderquist J, Wijma B, Thorbert G, Wijma K. Risk factors in pregnancy for posttraumatic stress and depression after childbirth. BJOG An Int J Obstet Gynaecol. 2009;116(5):672-680. doi:10.1111/j.1471-0528.2008.02083.x

6. Milgrom J, Gemmill AW, Bilszta JL, et al. Antenatal risk factors for postnatal depression: A large prospective study. J Affect Disord. 2008;108(1-2):147-157. doi:10.1016/j.jad.2007.10.014

7. Verkerk GJM, Denollet J, Van Heck GL, Van Son MJM, Pop VJM. Personality factors as determinants of depression in postpartum women: A prospective 1-year follow-up study. Psychosom Med. 2005;67(4):632-637. doi:10.1097/01.psy.0000170832.14718.98

8. Eckerdal P, Georgakis MK, Kollia N, Wikström AK, Högberg U, Skalkidou A. Delineating the association between mode of delivery and postpartum depression symptoms: a longitudinal study. Acta Obstet Gynecol Scand. 2018;97(3):301-311. doi:10.1111/aogs.13275

9. Blom EA, Jansen PW, Verhulst FC, et al. Perinatal complications increase the risk of postpartum depression. The Generation R Study. BJOG An Int J Obstet Gynaecol. 2010;117(11):1390-1398. doi:10.1111/j.1471-0528.2010.02660.x

10. Ghaedrahmati M, Kazemi A, Kheirabadi G, Ebrahimi A, Bahrami M. Postpartum depression risk factors: A narrative review. J Educ Health Promot. 2017;6:60. doi:10.4103/jehp.jehp_9_16

11. Smorti M, Ponti L, Pancetti F. A Comprehensive Analysis of Post-partum Depression Risk Factors: The Role of Socio-Demographic, Individual, Relational, and Delivery Characteristics. Front Public Heal. 2019;7. doi:10.3389/fpubh.2019.00295

12. Afzali MH, Sunderland M, Batterham PJ, Carragher N, Calear A, Slade T. Network approach to the symptom-level association between alcohol use disorder and posttraumatic stress disorder. Soc Psychiatry Psychiatr Epidemiol. 2017;52(3):329339. doi:10.1007/s00127-016-1331-3

13. Joshi H, Fitzsimons E. The UK millennium cohort study: The making of a multipurpose resource for social science and policy. Longit Life Course Stud. 2016;7(4):409-430. doi:10.14301/1lcs.v7i4.410

14. Schoon I, Sacker A, Hope S, Collishaw S, Maughan B. Children's development in the family environment. In: Children of the 21st Century: From Birth to Nine Months. Policy Press; 2005:159-174. doi:10.2307/j.ctt9qgpbk.13

15. Rosenberg R. Millennium Cohort Study MCS1: Guide to Derived Variables. Published online 2012.

16. Jones E, Ketende S, Sosthenes C. Millennium cohort study: User guide to analysing 
MCS data using SPSS. Published online 2010.

17. Haslbeck JMB, Waldorp LJ. mgm: Estimating Time-Varying Mixed Graphical Models in High-Dimensional Data. Published online October 23, 2015. Accessed June 26, 2020. http://arxiv.org/abs/1510.06871

18. Johnson J, Calderwood L, Mostafa T, Platt L, Rosenberg R, Smith K. A Guide to the Datasets (Eighth Edition) Ii.; 2014. Accessed October 24, 2020. www.cls.ioe.ac.uk

19. Epskamp S, Borsboom D, Fried EI. Estimating psychological networks and their accuracy: A tutorial paper. Behav Res Methods. 2018;50(1):195-212. doi:10.3758/s13428-017-0862-1

20. Trumello C, Candelori C, Cofini M, et al. Mothers' depression, anxiety, and mental representations after preterm birth: A study during the infant's hospitalization in a neonatal intensive care unit. Front Public Heal. 2018;6(DEC):359. doi:10.3389/fpubh.2018.00359

21. Kokubu M, Okano A, Sugiyama T. Postnatal depression, maternal bonding failure, and negative attitudes towards pregnancy: A longitudinal study of pregnant women in Japan. Arch Womens Ment Health. 2012;15(3):211-216. doi:10.1007/s00737-0120279-x

22. Dinas PC, Koutedakis Y, Flouris AD. Effects of exercise and physical activity on depression. Ir J Med Sci. 2011;180(2):319-325. doi:10.1007/s11845-010-0633-9

23. Bränn E, Papadopoulos F, Fransson E, et al. Inflammatory markers in late pregnancy in association with postpartum depression-A nested case-control study.

Psychoneuroendocrinology. 2017;79:146-159. doi:10.1016/j.psyneuen.2017.02.029

24. Çintesun E, Akar S, Gul A, et al. Subclinical inflammation markers in hyperemesis gravidarum and ketonuria: A case-control study. J Lab Physicians. 2019;11(02):149153. doi:10.4103/jlp.jlp_151_18

25. Cui M, Kimura T, Ikehara S, et al. Prenatal tobacco smoking is associated with postpartum depression in Japanese pregnant women: The japan environment and children's study. J Affect Disord. 2020;264:76-81. doi:10.1016/j.jad.2019.11.145

26. Trussell J, Vaughan B, Stanford J. Are all contraceptive failures unintended pregnancies? Evidence from the 1995 National Survey of Family Growth. Fam Plann Perspect. 1999;31(5). doi:10.2307/2991573

27. Lindquist A, Kurinczuk JJ, Redshaw M, Knight M. Experiences, utilisation and outcomes of maternity care in England among women from different socio-economic groups: Findings from the 2010 National Maternity Survey. BJOG An Int J Obstet Gynaecol. 2015;122(12):1610-1617. doi:10.1111/1471-0528.13059

28. Gresham E, Forder P, Chojenta CL, Byles JE, Loxton DJ, Hure AJ. Agreement between self-reported perinatal outcomes and administrative data in New South Wales, Australia. BMC Pregnancy Childbirth. 2015;15(1):161. doi:10.1186/s12884-0150597-x

29. Falkegård M, Schirmer H, Løchen M-L, Øian P, Acharya G. The validity of selfreported information about hypertensive disorders of pregnancy in a population-based survey: the Tromsø Study. Acta Obstet Gynecol Scand. 2015;94(1):28-34. doi:10.1111/aogs.12514

30. Sit DKY, Wisner KL. Identification of postpartum depression. Clin Obstet Gynecol. 2009;52(3):456-468. doi:10.1097/GRF.0b013e3181b5a57c 
Table 1. Population characteristics

\begin{tabular}{|c|c|c|c|c|}
\hline Variable & Mean & $S D$ & Range & $N$ \\
\hline Age & 28.79 & 5.86 & $14-48$ & 17525 \\
\hline \multirow[t]{2}{*}{ Postnatal Psychological Distress } & 1.62 & 1.73 & $0-9$ & 17531 \\
\hline & Category & & $N$ & $\%$ \\
\hline \multirow[t]{3}{*}{ Ethnicity } & White & & 15034 & 85.9 \\
\hline & Other Ethnicity & & 2465 & 14.1 \\
\hline & Missing & & 32 & \\
\hline \multirow[t]{3}{*}{ College Qualification } & Yes & & 14877 & 85.0 \\
\hline & No & & 2633 & 15.0 \\
\hline & Missing & & 21 & \\
\hline \multirow[t]{3}{*}{ First Time Mother } & Yes & & 10129 & 57.8 \\
\hline & No & & 7398 & 42.2 \\
\hline & Missing & & 4 & \\
\hline \multirow[t]{3}{*}{ Single Parent } & Yes & & 3006 & 17.2 \\
\hline & No & & 14521 & 82.8 \\
\hline & Missing & & 4 & \\
\hline \multirow[t]{6}{*}{ Income } & Lowest Quintile (Lowest Income) & & 4241 & 24.3 \\
\hline & $20-<40 \%$ & & 3879 & 22.2 \\
\hline & $40-<60 \%$ & & 3352 & 19.2 \\
\hline & $60-<80 \%$ & & 3136 & 17.9 \\
\hline & Highest Quintile (Highest Income) & & 2878 & 16.5 \\
\hline & Missing & & 45 & \\
\hline \multirow[t]{11}{*}{ Deprivation } & Lowest Decile (Most Deprived) & & 2932 & 16.7 \\
\hline & $10-<20 \%$ & & 2552 & 14.6 \\
\hline & $20-<30 \%$ & & 2220 & 12.7 \\
\hline & $30-<40 \%$ & & 1792 & 10.2 \\
\hline & $40-<50 \%$ & & 1546 & 8.8 \\
\hline & $50-<60 \%$ & & 1412 & 8.1 \\
\hline & $60-<70 \%$ & & 1177 & 6.7 \\
\hline & $70-<80 \%$ & & 1247 & 7.1 \\
\hline & $80-<90 \%$ & & 1323 & 7.5 \\
\hline & Highest Decile (Least Deprived) & & 1329 & 7.6 \\
\hline & Missing & & 1 & \\
\hline \multirow[t]{2}{*}{ History of Depression and Anxiety } & Yes & & 4362 & 24.9 \\
\hline & No & & 13168 & 75.1 \\
\hline
\end{tabular}

Note: Mean and standard deviations $(S D)$ were corrected for the survey design of the MCS. 
Table 2. Population characteristics of perinatal risk factors

\begin{tabular}{|c|c|c|c|c|}
\hline Variable & Mean & $S D$ & Range & $N$ \\
\hline Breastfeeding Duration in Weeks & 11.83 & 14.35 & $0-47.14$ & 17304 \\
\hline Birthweight in Kilograms & 3.38 & 0.57 & $0.39-7.23$ & 17513 \\
\hline Gestational Age in Weeks & 39.42 & 1.95 & $24-43$ & 17376 \\
\hline \multirow{2}{*}{ Age Baby Home from Hospital in Days } & 4.07 & 10.16 & $0-270$ & 17510 \\
\hline & Category & & $N$ & $\%$ \\
\hline \multirow[t]{3}{*}{ Planned Pregnancy } & Yes & & 9473 & 54.1 \\
\hline & No & & 8033 & 45.9 \\
\hline & Missing & & 25 & \\
\hline \multirow[t]{3}{*}{ Fertility Treatment } & Yes & & 411 & 2.5 \\
\hline & No & & 17092 & 97.7 \\
\hline & Missing & & 28 & \\
\hline \multirow[t]{3}{*}{ Received Antenatal Care } & Yes & & 16916 & 96.5 \\
\hline & No & & 608 & 3.5 \\
\hline & Missing & & 7 & \\
\hline \multirow[t]{3}{*}{ Attended Antenatal Classes } & Yes & & 6013 & 35.5 \\
\hline & No & & 10903 & 64.5 \\
\hline & Missing & & 615 & \\
\hline \multirow[t]{6}{*}{ Happiness Levels about the Pregnancy } & Very Happy & & 9826 & 56.2 \\
\hline & Happy & & 4561 & 26.1 \\
\hline & Neutral & & 1148 & 6.6 \\
\hline & Unhappy & & 1342 & 7.7 \\
\hline & Very Unhappy & & 591 & 3.4 \\
\hline & Missing & & 63 & \\
\hline \multirow[t]{4}{*}{ Place of Birth } & Hospital & & 17153 & 97.9 \\
\hline & Home & & 339 & 1.9 \\
\hline & Other & & 36 & 0.2 \\
\hline & Missing & & 3 & \\
\hline \multirow[t]{6}{*}{ Type of Delivery } & Normal & & 12033 & 68.6 \\
\hline & Assisted & & 1688 & 9.6 \\
\hline & Planned Cesarean & & 1616 & 9.2 \\
\hline & Emergency Cesarean & & 2119 & 12.1 \\
\hline & Other & & 79 & 0.5 \\
\hline & Missing & & 5 & \\
\hline \multirow[t]{6}{*}{ Type of Pain Relief } & None & & 1371 & 8.1 \\
\hline & Gas and Air & & 12192 & 71.6 \\
\hline & Epidural & & 2115 & 12.4 \\
\hline & Opiate Injection & & 647 & 3.8 \\
\hline & Other & & 704 & 4.1 \\
\hline & Missing & & 502 & \\
\hline \multirow[t]{3}{*}{ Labour Induced } & Yes & & 5447 & 31.1 \\
\hline & No & & 12069 & 68.9 \\
\hline & Missing & & 15 & \\
\hline \multirow[t]{3}{*}{ Labour Complication: Abnormal Lie } & Yes & & 973 & 5.6 \\
\hline & No & & 16551 & 94.4 \\
\hline & Missing & & 7 & \\
\hline \multirow[t]{3}{*}{ Labour Complication: Very Long Labour } & Yes & & 1237 & 7.1 \\
\hline & No & & 16287 & 92.9 \\
\hline & Missing & & 7 & \\
\hline \multirow[t]{3}{*}{ Labour Complication: Very Rapid Labour } & Yes & & 435 & 2.5 \\
\hline & No & & 17089 & 97.5 \\
\hline & Missing & & 7 & \\
\hline
\end{tabular}




\begin{tabular}{|c|c|c|c|}
\hline Labour Complication: Fetal Distress & $\begin{array}{l}\text { Yes } \\
\text { No } \\
\text { Missing }\end{array}$ & $\begin{array}{l}2592 \\
14932 \\
7\end{array}$ & $\begin{array}{l}14.8 \\
85.2\end{array}$ \\
\hline Illness: Infection & $\begin{array}{l}\text { Yes } \\
\text { No } \\
\text { Missing }\end{array}$ & $\begin{array}{l}1307 \\
16218 \\
6\end{array}$ & $\begin{array}{l}7.5 \\
92.5\end{array}$ \\
\hline Illness: Hyperemesis Gravidarum & $\begin{array}{l}\text { Yes } \\
\text { No } \\
\text { Missing }\end{array}$ & $\begin{array}{l}1007 \\
16518 \\
6\end{array}$ & $\begin{array}{l}5.7 \\
94.3\end{array}$ \\
\hline Illness: Diabetes & $\begin{array}{l}\text { Yes } \\
\text { No } \\
\text { Missing }\end{array}$ & $\begin{array}{l}284 \\
17241 \\
6 \\
\end{array}$ & $\begin{array}{l}1.6 \\
98.4\end{array}$ \\
\hline Illness: Preeclampsia & $\begin{array}{l}\text { Yes } \\
\text { No } \\
\text { Missing }\end{array}$ & $\begin{array}{l}1278 \\
16247 \\
6 \\
\end{array}$ & $\begin{array}{l}7.3 \\
92.7\end{array}$ \\
\hline Illness: Anemia & $\begin{array}{l}\text { Yes } \\
\text { No } \\
\text { Missing }\end{array}$ & $\begin{array}{l}447 \\
17078 \\
6\end{array}$ & $\begin{array}{l}2.6 \\
97.4\end{array}$ \\
\hline Illness: Bleeding in Early Pregnancy & $\begin{array}{l}\text { Yes } \\
\text { No } \\
\text { Missing }\end{array}$ & $\begin{array}{l}1084 \\
16441 \\
6 \\
\end{array}$ & $\begin{array}{l}6.2 \\
93.8\end{array}$ \\
\hline Illness: Bleeding in Late Pregnancy & $\begin{array}{l}\text { Yes } \\
\text { No } \\
\text { Missing }\end{array}$ & $\begin{array}{l}628 \\
16897 \\
6\end{array}$ & $\begin{array}{l}3.6 \\
96.4\end{array}$ \\
\hline Baby went to Special Care & $\begin{array}{l}\text { Yes } \\
\text { No } \\
\text { Missing }\end{array}$ & $\begin{array}{l}1418 \\
16106 \\
7\end{array}$ & $\begin{array}{l}8.1 \\
91.9\end{array}$ \\
\hline Smoked during Pregnancy & $\begin{array}{l}\text { Yes } \\
\text { No } \\
\text { Missing }\end{array}$ & $\begin{array}{l}3202 \\
11716 \\
0\end{array}$ & $\begin{array}{l}21.5 \\
78.5\end{array}$ \\
\hline Sex of the Baby & $\begin{array}{l}\text { Female } \\
\text { Male } \\
\text { Missing }\end{array}$ & $\begin{array}{l}8500 \\
9026 \\
5\end{array}$ & $\begin{array}{l}48.5 \\
51.5\end{array}$ \\
\hline
\end{tabular}

Note: Mean and standard deviations $(S D)$ were corrected for the survey design of the MCS. 
Table 3: Regression parameter estimates for risk factors associated with PD in the multivariate analysis

\begin{tabular}{|c|c|c|}
\hline Risk Factor & B (95\% CI) & $p$ \\
\hline Planned Pregnancy (Reference: Yes) & $1.56(1.43-1.69)$ & \\
\hline No & $0.19(0.13-0.26)$ & $<.001 * *$ \\
\hline Received Antenatal Care (Reference: Yes) & $1.63(1.50-1.76)$ & \\
\hline No & $0.23(0.03-0.43)$ & $.02 *$ \\
\hline Happiness Levels about the Pregnancy & $1.89(1.75-2.02)$ & \\
\hline Linear Trend & $0.51(0.38-0.63)$ & $<.001 * *$ \\
\hline Type of Pain Relief (Reference: None) & $1.60(1.44-1.75)$ & \\
\hline Gas and Air & $0.06(-0.07-0.18)$ & .37 \\
\hline Epidural & $0.05(-0.05-0.16)$ & .32 \\
\hline Opiate Injection & $-0.02(-0.18-0.15)$ & .85 \\
\hline Other & $0.23(0.08-0.39)$ & $<.001 * *$ \\
\hline Labour Complication: Abnormal Lie (Reference: No) & $1.64(1.51-1.76)$ & \\
\hline Yes & $0.19(0.07-0.31)$ & $<.001 * *$ \\
\hline Labour Complication: Very Long Labour (Reference: No) & $1.63(1.50-1.76)$ & \\
\hline Yes & $0.13(0.03-0.24)$ & $.01 *$ \\
\hline Labour Complication: Fetal Distress (Reference: No) & $1.64(1.51-1.77)$ & \\
\hline Yes & $0.08(0.00-0.15)$ & $.05^{*}$ \\
\hline Illness: Infection (Reference: No) & $1.64(1.51-1.77)$ & \\
\hline Yes & $0.36(0.24-0.48)$ & $<.001 * *$ \\
\hline Illness: Hyperemesis Gravidarum (Reference: No) & $1.63(1.50-1.76)$ & \\
\hline Yes & $0.31(0.18-0.44)$ & $<.001 * *$ \\
\hline Illness: Anemia (Reference: No) & $1.64(1.51-1.77)$ & \\
\hline Yes & $0.22(0.07-0.36)$ & $<.001 * *$ \\
\hline Illness: Bleeding in Early Pregnancy (Reference: No) & $1.64(1.51-1.77)$ & \\
\hline Yes & $0.13(0.02-0.25)$ & $.03 *$ \\
\hline Illness: Bleeding in Late Pregnancy (Reference: No) & $1.65(1.52-1.77)$ & \\
\hline Yes & $0.16(0.02-0.30)$ & $.02 *$ \\
\hline Baby went to Special Care (Reference: No) & $1.62(1.50-1.75)$ & \\
\hline Yes & $0.26(0.16-0.36)$ & $<.001^{* *}$ \\
\hline Smoked during Pregnancy (Reference: No) & $1.63(1.50-1.76)$ & \\
\hline Yes & $0.17(0.09-0.25)$ & $<.001 * *$ \\
\hline Birthweight in Kilograms & $1.83(1.62-2.04)$ & \\
\hline Linear Trend & $-0.06(-0.11--0.01)$ & $.02 *$ \\
\hline Gestational Age in Weeks & $2.35(1.78-2.92)$ & \\
\hline Linear Trend & $-0.02(-0.03--0.00)$ & $.01 *$ \\
\hline Age Baby Home from Hospital & $1.62(1.49-1.75)$ & \\
\hline Linear Trend & $0.01(0.00-0.01)$ & $<.001 * *$ \\
\hline Sex of Baby (Reference: Female) & $1.62(1.49-1.74)$ & \\
\hline Male & $0.06(0.01-0.11)$ & $.02 *$ \\
\hline
\end{tabular}


Table 4: Edge weight, bootstrapped mean weight and $95 \%$ confidence interval's (CI) and standardized parameter estimates $(b)$ for nodes sharing an edge with maternal psychological distress in the adjusted model

\begin{tabular}{|c|c|c|c|c|c|}
\hline \multirow[b]{2}{*}{ Node } & \multirow[b]{2}{*}{ Weight } & \multirow{2}{*}{$\begin{array}{l}\text { Bootstrapped } \\
\text { Mean Weight }\end{array}$} & \multicolumn{2}{|c|}{ 95\% CI's } & \multirow[b]{2}{*}{$\boldsymbol{b}$} \\
\hline & & & Lower & Upper & \\
\hline Happiness Levels about Pregnancy & 0.084 & 0.084 & 0.069 & 0.100 & 0.095 \\
\hline Smoking during Pregnancy & 0.026 & 0.020 & -0.009 & 0.060 & 0.029 \\
\hline Infection during Pregnancy & 0.071 & 0.066 & 0.024 & 0.118 & 0.090 \\
\hline Hyperemesis Gravidarum & 0.068 & 0.062 & 0.013 & 0.123 & 0.083 \\
\hline Baby went to Special Care & 0.048 & 0.035 & -0.004 & 0.099 & 0.062 \\
\hline Income $^{1}$ & -0.025 & -0.014 & -0.055 & 0.005 & -0.036 \\
\hline Deprivation $^{2}$ & -0.028 & -0.026 & -0.051 & -0.005 & -0.039 \\
\hline Maternal Ethnicity & 0.101 & 0.100 & 0.062 & 0.140 & 0.118 \\
\hline History of Depression or Anxiety & 0.574 & 0.572 & 0.545 & 0.603 & 0.764 \\
\hline
\end{tabular}

Note: ${ }^{1}$ baseline $=$ lowest income, ${ }^{2}$ baseline $=$ most deprived 


\section{Figure Legends}

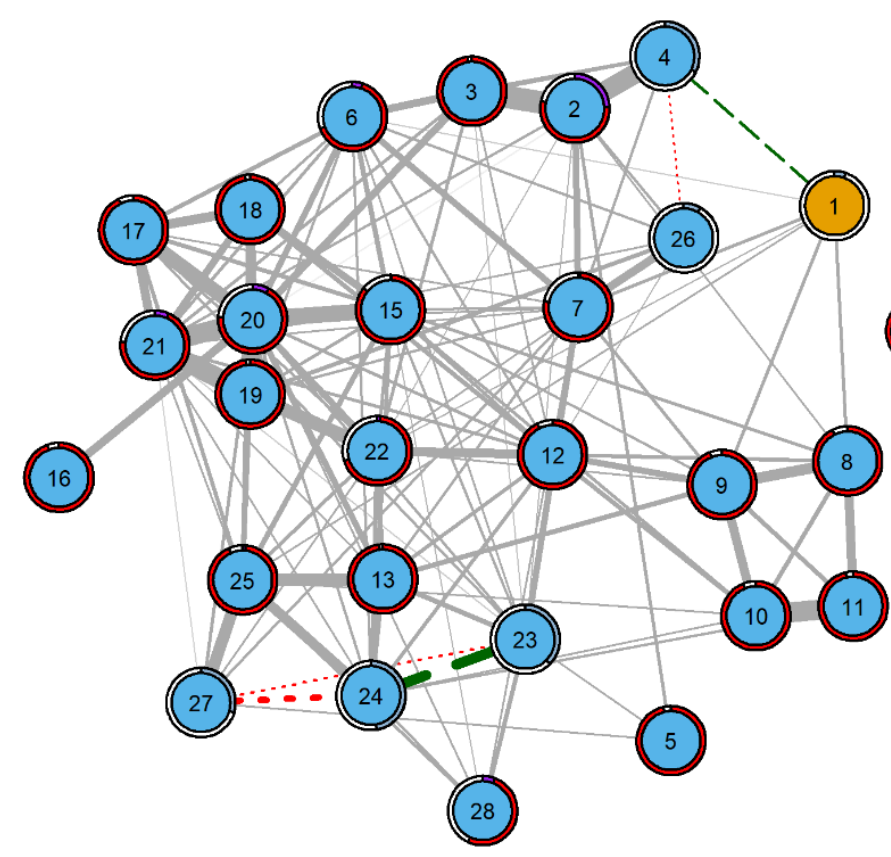

Depression

- 1: Maternal Psychological Distress

Risk Factors

- 2: Planned Pregnancy

- 3: Fertility Treatment

- 4: Feelings when became Pregnant

- 5: Received Antenatal Care

- 6: Attended Antenatal Classes

- 7: Smoking during Pregnancy

- 8: Illness: Infection

- 9: Illness: Hyperemesis Gravidarum

- 10: Illness: Bleeding Early

- 11: Illness: Bleeding Late

- 12: Illness: Preeclampsia

- 13: Illness: Diabetes

- 14: Illness: Anaemia

- 15: Labour Complication: Foetal Distress

- 16: Labour Complication: Abnormal Lie

- 17: Labour Complication: Long Labour

- 18: Labour Complication: Rapid Labour

- 19: Place of Birth

- 20: Type of Delivery

- 21: Type of Pain Relief

- 22: Labour Induced

- 23: Birthweight in $\mathrm{kg}$

- 24: Gestational Age in Days

- 25: Baby went to Special Care

- 26: Breastfeeding Duration in Weeks

- 27: Age Baby Home in Days

- 28: Sex of Baby

Fig. 1 Network displaying the relations between maternal psychological distress and perinatal risk factors. The width of the edges is proportional to the absolute weight of the edge-parameter, visualizing the strength of the relationship between two variables (the wider the edge, the stronger the association). Green edges (dashed) indicate a positive relation; red edges (dotted) a negative relation and grey edges (solid) indicate a relation between categorical variables. The ring around the nodes indicates the accuracy, that is, variance explained by all other nodes in the model. The blue ring shows the proportion of explained variance for continuous variables. For categorical variables, the purple part of the ring indicates the accuracy of the intercept model. The red part of the ring is the additional accuracy achieved by all remaining variables. The sum of both is the accuracy of the full model. 


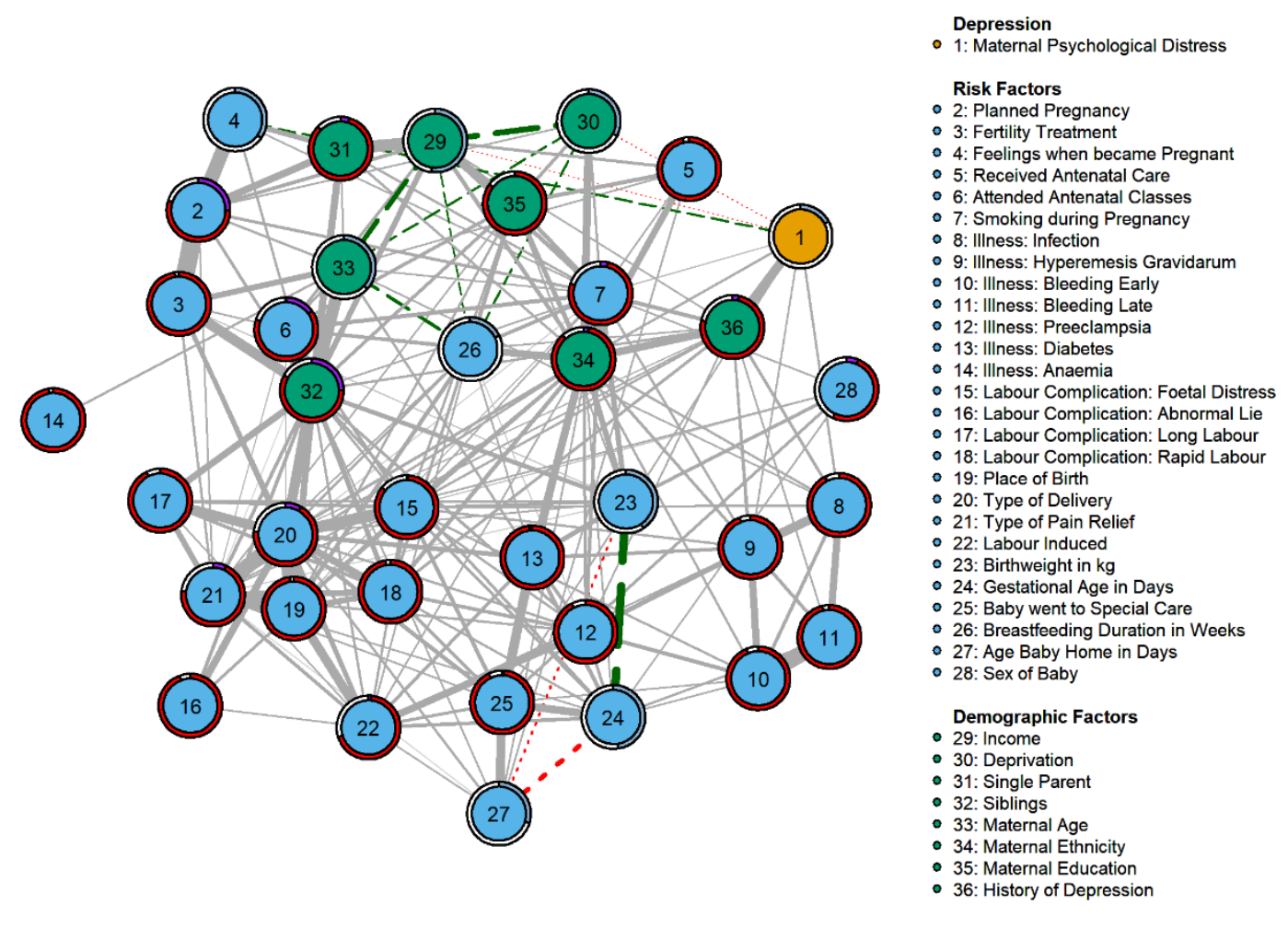

Fig. 2 Network displaying the relations between maternal psychological distress and perinatal risk factors after adding demographic variables and history of depression or anxiety. The width of the edges is proportional to the absolute weight of the edge-parameter, visualizing the strength of the relations between two variables (the wider the edge, the stronger the association). Green edges (dashed) indicate a positive relation; red edges (dotted) a negative relation and grey edges (solid) indicate a relation between categorical variables. The ring around the nodes indicates the accuracy, that is, variance explained by all other nodes in the model. The blue ring shows the proportion of explained variance for continuous variables. For categorical variables, the purple part of the ring indicates the accuracy of the intercept model. The red part of the ring is the additional accuracy achieved by all remaining variables. The sum of both is the accuracy of the full model. 


\section{Supporting Information Legends}

Rutter Malaise Inventory: additional information on scoring of the RMI as well as on specificity and sensitivity

Maternal Illness During Pregnancy: additional information on wording of interview questions for maternal illness during pregnancy

Statistical Analysis: additional information on how the analysis was conducted and extra information on graphical models

Table S1: Unadjusted and adjusted regression parameters for all risk factors

Table S2: Edge weights and bootstrapped 95\% confidence interval's (CI) for all potential edges with maternal psychological distress

Table S3: Edge weights and bootstrapped 95\% confidence interval's (CI) for all potential edges with maternal psychological distress for the fully adjusted model 